\title{
The Long-Run Information Effect of Central Bank Communication*
}

\author{
Stephen Hansen ${ }^{\dagger} \quad$ Michael McMahon ${ }^{\ddagger} \quad$ Matthew Tong§
}

August 21, 2019

\begin{abstract}
Why do long-run interest rates respond to central bank communication? Whereas existing explanations imply a common set of signals drives short and long-run yields, we show that news on economic uncertainty can have increasingly large effects along the yield curve. To evaluate this channel, we use the publication of the Bank of England's Inflation Report, from which we measure a set of highdimensional signals. The signals that drive long-run interest rates do not affect short-run rates and operate primarily through the term premium. This suggests communication plays an important role in shaping perceptions of long-run uncertainty.
\end{abstract}

Keywords: Monetary Policy, Communication, Machine Learning

JEL Codes: E52, E58, C55

*Omiros Papaspiliopoulos and David Rossell provided numerous helpful suggestions on the statistical methodologies used in this paper. We thank our discussants at different conferences - Jan Marc Berk, Jenny Tang (twice) and Jonathan Talmi. We would like to additionally thank, for comments, discussion and suggestions, Michael Ehrmann, Refet Gürkaynak, Emi Nakamura, Alessandro Riboni, and Jon Steinsson, as well as participants at numerous conferences and seminars. This paper has been prepared while McMahon was under the Lamfalussy Fellowship Program sponsored by the ECB. This views expressed here do not necessarily represent the views of the Bank of England, the Monetary Policy Committee, Financial Policy Committee, the ECB, the Eurosystem or anyone else other than the authors. Any errors remain ours alone.

†Imperial College Business School and CEPR. Email: stephen.hansen@imperial.ac.uk

${ }^{\ddagger}$ University of Oxford, CEPR, CfM (LSE), CAGE (Warwick) and CAMA (ANU). Email: michael. mcmahon@economics.ox.ac.uk

§Bank of England. Email: matthew.tong@bankofengland.co.uk 


\section{Introduction}

2 For the last two decades, central banks have increasingly used public communication to

3

4

5

6

7

8 
certainty around economic conditions, and thereby generating a change in the long-run term premium. This channel operates not by changing long-run expectations of economic conditions, but by changing the perceived variance of those conditions. The existing information effect literature focuses on news that changes market expectations of levels (including of highly-persistent fundamentals). Our theoretical framework shows that such signals should move short-run interest rates by at least as much as long-run rates. In contrast, the model shows that uncertainty signals can move long-run interest rates by more than short-run rates. Furthermore, the effect of uncertainty signals comes via the long-run term premium, which can move independently of short-run expectations. The distinguishes the uncertainty channel from Hanson and Stein (2015).

To test for the relevance of these different channels, we use the publication of the Bank of England's Inflation Report (IR) from February 1998 through May 2015. The IR contains information about the Bank of England's economic forecasts, but rarely provides explicit forward guidance on future policy. Moreover, during our sample period, the IR was published according to a fixed, quarterly schedule one week after the announcement of the policy decision. It therefore constitutes a policy-free information shock that allows us to directly assess the market impact of news about the Bank's views without having to decompose a policy change into separate information and policy shock components as in Miranda-Agrippino and Ricco (2015) and Jarociński and Karadi (2019).

Our empirical strategy decomposes each IR into a set of relatively high-dimensional numeric and narrative signals, and identifies which signals drive market rate reactions on IR publication days across different rate maturities and rate components (i.e. expectations and term premia). The numeric signals include the Bank's inflation and GDP forecasts, as well as the variance and skew around those forecasts. To obtain narrative signals, we use latent Dirichlet allocation (Blei et al. 2003, and previously applied in monetary economics by Hansen and McMahon 2016 and Hansen et al. 2018) to represent each Report's text as a distribution over a set of topics. To test whether the narrative contains news beyond the numeric forecasts, we employ a permutation test that strongly rejects the null of no news. This allows us to use the richness of the narrative to assess 
whether different signals drive short-run and long-run market rates.

Our second contribution is to provide robust evidence in favor of the uncertainty channel as an important factor in explaining why long-run rates react to IR publication. First, signals from higher moments of the forecasts explains an increasing proportion of interest rate variation at longer horizons. Second, we use the narrative signals in three ways to show that uncertainty signals drive the change in long-run interest rates:

1. We identify the narrative signals that drive yield movements at each maturity using a bootstrap procedure. There is little overlap between the signals that drive shortrun interest rate changes and those that drive long-run changes. Moreover, the narrative signals that explain long-run rates feature words suggestive of uncertainty.

2. We conduct a placebo test in which we replace the key maturity-specific narrative signals with the key signals from other maturities. The key long-run (short-run) signals explain little to none of the residual variance for short-run (long-run) yields.

3. We repeat the analysis splitting the overall yield into expectations and term premium components; the expectations (term premium) component dominates the overall variation for short-maturity (long-maturity) bonds. The key signals that drive expectations are similar across the yield curve, and different to those that drive term premiums. The key signals for short-run expectations do not explain changes in the long-run term premium.

The results suggest that while the standard information effect appears to operate on long-run level expectations, it does not explain most of the overall long-run market rate reaction to the IR. Instead, the evidence is consistent with an uncertainty communication channel as the primary source of the reaction, via changes in the term premium. Unlike in Hanson and Stein (2015), this term premium effect is the direct result of news rather than an indirect result of trading activity.

Our findings are also related to a growing empirical literature on the effects of monetary policy events on term premiums. For example, Jarociński and Karadi (2019) find no effect of monetary policy surprises on term premiums in the US. By contrast, a growing 
literature finds important effects. Bundick et al. (2017) show that shocks to uncertainty about future interest rate decisions yield significant moves in long-term term premiums in the US. And Cieslak and Schrimpf (2019) show that monetary events in the US, Euro Area, UK and Japan are associated with risk preference shocks identified off the movement in term premiums across the yield curve. This literature does not emphasise the role of central bank communication about uncertainty as driving the effects. In fact, the findings could be unrelated to information effects as in the risk premium channel of monetary policy in Drechsler et al. (2018). Tang (2015) and Leombroni et al. (2018) link information effects from central bank communication to long-term interest rate movements with an explicit role for uncertainty. Unlike in our paper, the communication is about level expectations which then interact with given uncertainty that prevails at the time of the signal. In our paper, the central bank signals are themselves about uncertainty. Munday (2019) has recently shown that similar IR signals give influence second and third moments of expectations' distributions derived from options prices.

The main implication of our findings is that central bank communication affects market beliefs about long-run uncertainty. In our view, this channel has been underappreciated in the literature on monetary policy, but is something that central banks should take into account as part of their overall communication strategies, especially as there is increasing evidence that uncertainty has macroeconomic effects (Bloom (2009), Fernandez-Villaverde et al. (2011), Jurado et al. (2015), Baker et al. (2016)). Moreover, such a channel may become particularly important when the central bank is confronted with the lower bound on policy interest rates. Carvalho et al. (2016) find communication continued to have effects on longer-maturity bonds even when shorter-maturity bonds stopped responding once US interest rates reached their zero-lower bound.

This is related to the use of forward guidance. Our analysis pertains mostly to socalled 'Delphic' forward guidance, which Campbell et al. (2012) define as communicating a view on future economic conditions and at the same time describing a likely policy response to that view. Our paper shows that market reactions arise from communicating such views about economic conditions even in the absence of new information on policy 
reactions. Of course, the study of this channel does not rule out an effect from forward guidance that involves more explicit policy commitments ('Odyssean'). However, such forward guidance was not present the UK's Inflation Report. Moreover, temporary deviations from the typical reaction function are unlikely to move longer-term interest rate expectations unless such guidance signalled a persistent change in an economic fundamental such as the real interest rate or inflation target. Even persistent changes in how the central bank will react to economic conditions are unlikely to explain changes in long-run expectations as both deviations of inflation from target and the output gap are typically forecast to be zero sufficiently far out.

Finally, a broader policy implication is the use of narrative as an instrument for managing expectations. Shiller (2017) introduced the notion of Narrative Economics, which emphasizes the role of narratives in spreading beliefs. In monetary policy, central banks have an important role in shaping public narrative (Haldane and McMahon 2018), and our work suggests this includes narratives about economic uncertainty.

From a methodological perspective, we illustrate how to combine event study analysis with a high-dimensional set of regressors that measure signals from unstructured text data. Our framework allows us to distinguish channels based on heterogeneity in the correlation patterns across yields. Given the popularity of event studies in the monetary policy literature, and the preponderance of text that accompanies many central bank communication events, the methods we propose have broad applicability. For example, Gürkaynak et al. (2018) find that the change in interest rates around central bank communication events in the US is only partially captured by headline numeric information. Our approach allows researchers to directly analyze the 'missing' information not accounted for in traditional analysis.

The paper is organized as follow. Section 2 describes the Inflation Report and the yield curve data; Section 3 introduces a framework that incorporates information effects on levels and uncertainty; and Section 4 explains how we measure the numeric and narrative information in the IR. Section 5 presents our core empirical findings, and Section 5.3 presents robustness results. Section 6 concludes. 


\section{IR Communication and the Yield Curve}

2 In this section we motivate the focus on the IR and the information it delivers. We 3 then discuss the interest rate data we use and show that the Report's publication has an 4 impact on market rates at a range of maturities.

\section{${ }_{5} 2.1$ The Inflation Report}

6 Following the adoption of inflation targeting in the UK in 1993, the IR has been published 7 quarterly by the Bank of England. When the Bank of England was granted operational 8 independence for monetary policy in May 1997, a nine-person Monetary Policy Commit9 tee (MPC) was established to set policy on a monthly basis in a way consistent with

10 meeting its inflation target remit. Since independence, the IR is the quarterly communication vehicle for the MPC and contains the Committee's forecasts for GDP growth and inflation. In its own words, the IR "sets out the economic analysis and inflation projections that the Monetary Policy Committee uses to make its interest rate decisions."

Our sample comprises 70 IR publications. It starts in February 1998 when the MPC began publishing forecasts on a consistent basis. During our sample, the IR was published one week after the announcement of the policy rate decision but before the publication of the minutes that explained the decision. Our sample ends in May 2015, after which the Bank moved to a new schedule where the IR is published at the same time as the policy rate and minutes, which makes isolating the impact of communication difficult.

The Inflation Report is a rich source of information. Its headline information is modal forecasts for GDP and inflation over the following two years (three years from August 2004 onwards), as well as distributional information around those modes in the form of a variance and skew. It presents these projections in the form of fan charts, with the numeric values for forecast distributions made publically available on the IR website alongside the graphical representation. The IR also contains extensive narrative information in the form of written text. Section 4 describes how we quantify the information in the IR.

The IR report is also important for what it does not contain, i.e. formal forward 


\footnotetext{
${ }^{3}$ Of course, as pointed out in Hansen and McMahon (2018), information about economic conditions can help market participants identify other drivers of the monetary policy decisions and thus may provide information on fundamentals beyond those conditions.

${ }^{4}$ We take a broader view of what Romer and Romer (2000) call the information effect. In their sample, the observed policy rate change was one of the main means by which markets could infer Fed forecasts. In this paper, the "information effect" includes any systematic market reaction to communication about economic fundamentals via any medium.

${ }^{5}$ In the Appendix $\mathrm{C}$, we show that there is meaningful variation in yields in response to the IR. For example, a quarter or more of IR publication dates lead to a change of at least five basis points for all our yields, with the proportion growing to nearly a half for three-year forward rates, and movements of ten basis points are not uncommon.
} 
speeches, but these do not systematically fall on IR publication days. However, on a number of days in our sample there is also the release of labour market data but we show in Section 5.3 that this information is orthogonal to the IR and does not affect our results. We, therefore, use the observed change in market interest rates on day $t$ to assess the news contained in IR publication. While the literature increasingly uses tight, intra-day windows around communication events, we use daily changes since it may take markets longer to incorporate the length and complexity of the IR.

[Figure 1 about here.]

For our analysis, we use data during the period January 1998 to July 2015 on market rates at four different maturities derived from UK government bond prices: the one-year spot rate; the three-year forward rate; the five-year forward rate; and the five-year ahead, five year forward rate (equivalent to the average forward rate five to ten years ahead). We use nominal rather than real rates because obtaining reliable short-run real rates during our sample in the UK is difficult. In Appendix I.3 we repeat the anlaysis on mediumand long-run real rates; the results are very similar to those with nominal rates.

Under standard asset pricing theory, we can write forward interest rates as a combination of an expectation and term premium. If investors were unconcerned about the risks around future interest rates, the term structure of interest rates - the 'yield curve' - should equal the expected path for short-term interest rates. This is often called the 'pure expectations hypothesis' and arises from the ability of investors to choose between buying a long-term bond or investing in a series of short-term bonds. In practice, however, market interest rates deviate from the pure expectations hypothesis, with the difference referred to as the 'term premium' (TP).

In some of the analysis, we distinguish between the effect that IR publication has on expectations and term premiums separately. Appendix B provides the details of our decomposition which uses an average of four different models to separate out the two components. In terms of the contribution of each component to explaining the overall variance in yields on IR publication days in our sample. The 1-year spot rate 
has relatively low variance (partly because our sample includes a period in which shortmaturity interest rates were at the effective lower bound) and the variance is driven mostly by the expectations component. The term premium plays an increasingly important role in accounting for movements in interest rates at longer horizons, and is the primary driver of changes in the five-year, five-year forward rate.

\section{Theoretical Channels for the Information Effect}

An important question is which information in the IR might generates market news, especially at longer maturities. In this section we present a simple model of how news about the outlook for economic conditions from the central bank can affect market interest rates. In particular, we include a stochastic form of uncertainty and show that central bank signals about uncertainty shocks can have an increasing impact on rates at greater maturities under a sufficiently high persistence of the underlying volatility. The formal proofs are contained in Appendix A.

This theoretical framework enables us to distinguish between three potential channels through which central bank communication could affect interest rates. We model two information effect channels; one concerning level expectations and the other concerning signals about uncertainty. The third channel, unmodelled here, is an investor demand channel as in Hanson and Stein (2015). The uncertainty channel is distinguished by the correlation structure it induces between signals across yields and their components.

\subsection{Model Environment}

As in macroeconomic models with forward-looking monetary policy, the central bank is assumed to set nominal interest rates as a function of forecasts of future economic conditions. For simplicity, we denote month- $m$ economic conditions as $\omega_{m} \in \mathbb{R}, \mathbb{E}\left[\omega_{m+h} \mid I_{m}^{\mathrm{CB}}\right]$ as the central bank's $h$-period-ahead forecast of economic conditions given its month $m$ information set $I_{m}^{\mathrm{CB}}$, and $\phi$ as the central bank's reaction coefficient. The short-term nominal interest rate in month $m$ is therefore $i_{m}=\phi \mathbb{E}\left[\omega_{m+h} \mid I_{m}^{\mathrm{CB}}\right]+\epsilon_{m}$, where the 
1

monetary policy shock is assumed to be $\epsilon_{m} \sim \mathcal{N}\left(0, \sigma_{\epsilon}^{2}\right)$ and uncorrelated across months.

This could be expanded to a vector of state variables $\boldsymbol{\omega}_{m}$ that included, for example, the expected output gap, expected inflation, and the equilibrium real interest rate, along with an associated vector of reaction coefficients $\phi$. The analysis below would then apply to each component separately, with the overall effect of central bank communication then being the sum over the effect on each component. We also ignore the effective lower bound on interest rates but return to this in Section 5.3.

We assume economic conditions $\omega_{m}$ evolve according to an $\mathrm{AR}(1)$ process

$$
\omega_{m}=\rho \omega_{m-1}+\underbrace{\mu_{m}+\varepsilon_{m}}_{=v_{m}} \text { where } 0<\rho \leq 1 \text {. }
$$

The shock to economic activity in month $m$, which we denote $v_{m}$, is comprised of two components. The first is $\mu_{m}$ which is drawn independently every month from $\mu_{m} \sim$ $\mathcal{N}\left(0, s^{2}\right)$. We assume the central bank obtains information that allows it to forecast the level of $\mu_{m}$ (details below). We therefore view uncertainty in $\mu_{m}$ as reducible with improvements in forecasting ability or new information. If the central bank's forecasting ability is high enough, we can even treat $\mu_{m}$ as fully observable.

In contrast, the central bank cannot forecast the level of the second component of the shock, $\varepsilon_{m}$. This represents the fundamental, or irreducible, uncertainty in the economy. We assume it is drawn independently each month from $\varepsilon_{m} \sim \mathcal{N}\left(0, \sigma_{m}^{2}\right)$, where the amount of fundamental uncertainty in the economy $\sigma_{m}^{2}$ is stochastic.

We follow much of the finance literature and model $\sigma_{m}^{2}$ as

$$
\log \sigma_{m}^{2}=\rho_{\sigma} \log \sigma_{m-1}^{2}+\left(1-\rho_{\sigma}\right) \log \sigma_{0}^{2}+u_{m} \text { where } 0<\rho_{\sigma} \leq 1
$$

\footnotetext{
Here $\sigma_{0}^{2}$ is some baseline level of uncertainty and we assume $u_{m} \sim \mathcal{N}\left(0, \sigma_{u}^{2}\right)$. This assumption generates a lognormal distribution for $\sigma_{m}^{2}$. It is important to note that, while the level of $\varepsilon_{m}$ is not forecastable, the level of uncertainty $\sigma_{m}^{2}$ is forecastable given information about shocks $u_{m^{\prime}}$ for $m^{\prime}<m$. This is an important mechanism that will lead to changes in long-run interest rates in the model.
} 
that leads to beliefs as specified in (3); $\sigma_{m+h}^{2}$ or, equivalently, the sequence of fundamental uncertainty shocks $u$ up to month $m+h$.

Market Information Set. Suppose the inflation report (IR) is published on day $t$, and let $m=m(t)$ be the month in which day $t$ falls. $I_{t}^{\mathrm{MK}}$ is defined as the market's information set on day $t$, and we assume that $I_{m}^{\mathrm{CB}}=I_{t}^{\mathrm{MK}}$, so that the information contained in the IR is a sufficient statistic for whatever else the market knows about the economy on day $t$. On day $t-1$, we assume the market has observed $\omega_{m}$, as well as signals on the values of $\mu$ within the forecast horizon that lead to beliefs

$$
\mu_{m+j} \mid I_{t-1}^{\mathrm{MK}} \sim \mathcal{N}\left(\widehat{\mu}_{m+j, t-1}^{\mathrm{MK}},\left(s_{m+j, t-1}^{\mathrm{MK}}\right)^{2}\right) \text { for } j=1, \ldots, h
$$

These signals may have come from the previous IR publication, or from independent market forecasts. In any case, we assume that the IR contains relevant additional information in the sense that $s_{m+j, t-1}^{\mathrm{MK}}>s_{m+j, t}^{\mathrm{MK}}=s_{m+j, m}^{\mathrm{CB}}$ : after IR publication, the market updates its beliefs from $\widehat{\mu}_{m+j, t-1}^{\mathrm{MK}}$ to $\widehat{\mu}_{m+j, t}^{\mathrm{MK}}=\widehat{\mu}_{m+j, m}^{\mathrm{CB}}$ and has lower forecast uncertainty about the value of $\mu_{m+j}$ for all $j=1, \ldots, h$.

On day $t-1$, we assume that the market has observed the sequence of shocks to fundamental uncertainty $u$ up to month $m+h-1$ only. Thus IR publication reveals $u_{m+h}$, which gives the market a new source of information for predicting $\sigma_{m+j}^{2}$ for all $j>h$. This is one particular way of modeling the idea that the IR contains news on fundamental uncertainty shocks. In a more complex model, the market would hold signals on day $t-1$ about $u_{m+1}, \ldots, u_{m+h}$ that IR publication then added to, as we have assumed for the $\mu$ terms, but the basic idea would be the same as in this setup. 7

In summary, the markets's day $t-1$ information set $I_{t-1}^{\mathrm{MK}}$ consists of: $\omega_{m} ; i_{m}$, the month $m$ policy rate published one week prior to the IR; signals for each $\mu$ in the forecast horizon that leads to beliefs as specified in (4); $\sigma_{m+h-1}^{2}$ or, equivalently, the sequence of fundamental uncertainty shocks $u$ up to month $m+h-1$.

\footnotetext{
${ }^{7}$ Another channel we do not model is that the IR could deliver indirect information about $\epsilon_{m}$, which is itself persistent. This variable in the interest rate rule can be thought of as capturing the central bank's preferences. However this is unlikely to be very persistent five to ten years ahead, when the membership of the MPC is likely to have changed completely.
} 


\section{3.2 Expectations Channel}

2 To assess the impact of information in the IR publication on interest rates, we distinguish 3 between two separate channels. The $k$-month-ahead forward rate is given by $f_{k, t}=$ ${ }_{4} \mathbb{E}\left[i_{m+k} \mid I_{t}^{\mathrm{MK}}\right]+\mathrm{TP}_{k}\left(I_{t}^{\mathrm{MK}}\right)$. Any observed change in $f_{k, t}$ must therefore arise from a 5 change in either expected future nominal rates or the term premium. We refer to the 6 expectations channel as the effect of IR publication on expected future interest rates, and 7 define

$$
\operatorname{EXP}_{m}(k) \equiv \mathbb{E}\left[i_{m+k} \mid I_{t}^{\mathrm{MK}}\right]-\mathbb{E}\left[i_{m+k} \mid I_{t-1}^{\mathrm{MK}}\right]
$$

8 The $k$-month-ahead policy rate is $i_{m+k}\left(I_{m+k}^{\mathrm{CB}}\right)=\phi \mathbb{E}\left[\omega_{m+k+h} \mid I_{m+k}^{\mathrm{CB}}\right]+\epsilon_{m+k}$, where

$$
\mathbb{E}\left[\omega_{m+k+h} \mid I_{m+k}^{\mathrm{CB}}\right]=\underbrace{\rho^{k+h} \omega_{m}+\sum_{j=1}^{k} \rho^{k+h-j} v_{m+j}}_{=\omega_{m+k}}+\sum_{j=k+1}^{k+h} \rho^{k+h-j} \widehat{\mu}_{m+j, m+k}^{\mathrm{CB}} .
$$

9 In month $m+k$, the central bank observes $\omega_{m+k}$ by assumption. The final term in (5) 10 is the central bank's forecasts for the shocks that will hit the economy within the month ${ }_{11} m+k$ forecasting horizon.

IR publication provides signals on the $v$ terms within the month- $m$ forecasting horizon, which will feed into the market expectations for $\omega_{m+k}$ for all $k$ due to the autoregressive process specified in (1). Second, it provides indirect signals on $\widehat{\mu}_{m+j, m+k}^{\mathrm{CB}}$ for $j=1, \ldots, h$.

Because the central bank is Bayesian, the market's best guess for $\widehat{\mu}_{m+j, m+k}^{\mathrm{CB}}$ after observing the IR is $\widehat{\mu}_{m+j, m}^{\mathrm{CB}}$. The overall effect is described in the following result.

Proposition 1 The impact of IR publication in month $m$ on interest rates through the expectations channel is

$$
E X P_{m}(k)=\phi \rho^{k} \sum_{j=1}^{h} \rho^{h-j}\left(\widehat{\mu}_{m+j, m}^{C B}-\mathbb{E}\left[\widehat{\mu}_{m+j, m}^{C B} \mid \widehat{\mu}_{m+j, t-1}^{M K}, i_{m}\right]\right)
$$

Moreover, if $\rho<1$ then $\operatorname{EXP}_{m}(k)$ is strictly decreasing in $k$ and $\lim _{k \rightarrow \infty} \operatorname{EXP}_{m}(k)=0$, while 20 if $\rho=1$ then $\operatorname{EXP}_{m}(k)$ is independent of $k$.

${ }_{21}$ On day $t-1$ the market has its own forecasts of future conditions $\widehat{\mu}_{m+j, t-1}^{\mathrm{MK}}$ and the current 
1 policy rate $i_{m}$ as relevant indicators of $\widehat{\mu}_{m+j, m}^{\mathrm{CB}}$ for $j=1, \ldots, h, 8$ which are in turn the 2 best predictors of (5) following IR publication. The size of the expectations channel effect 3 on market interest rates depends on the degree to which the market's views on $\widehat{\mu}_{m+j, m}^{\mathrm{CB}}$ 4 change after observing the IR.

5 Proposition 1 distinguishes between two cases. The first is $\rho<1$, which is plausible 6 for macro variables like inflation and GDP growth. Here the size of the expectations 7 channel effect is declining in maturity of the forward rate, as the influence of current 8 shocks on $\omega_{m+k}$ is declining in $k$ due to mean reversion in the autoregressive process. 9 The second case is $\rho=1$. For example, there is evidence that shocks to the natural rate of interest are highly persistent (Laubach and Williams 2003). In this case, long-run expectations of $\omega_{m+k}$ would react to updated beliefs of those shocks. Such information

\footnotetext{
${ }^{8} i_{m}$ provides information since it is a function of $\widehat{\mu}_{m+j, m}^{\mathrm{CB}}$ for $j=1, \ldots, h$. It does not perfectly reveal the central bank's information set since it also depends on the stochastic shock $\epsilon_{m}$.

${ }^{9}$ Another possibility is that the central bank could send separate short- and long-maturity-specific information that led market participants to update their views on each end of the yield curve independently, but this is not the case in the Inflation Report.
} 


\section{3.3 Uncertainty Channel}

2 The effect on forward nominal interest rates that information on uncertainty contained 3 in the IR publication - the uncertainty channel - defined as

$$
\mathrm{UNC}_{m}(k) \equiv \operatorname{Var}\left[i_{m+k} \mid I_{t}^{\mathrm{MK}}\right]-\operatorname{Var}\left[i_{m+k} \mid I_{t-1}^{\mathrm{MK}}\right]
$$

4 Any news contained in the IR that only affects $\mathrm{UNC}_{m}(k)$ and not $\operatorname{EXP}_{m}(k)$ must by def5 inition affect only the term premium. While we do not model the relationship between ${ }_{6} \mathrm{UNC}_{m}(k)$ and the term premium explicitly, a large macrofinance literature provides the7 oretical foundations for why uncertainty about economic conditions indeed affects the 8 term premium (e.g. Bansal and Shaliastovich 2013, Martin 2013).

In this section, we only provide results for impact of uncertainty on forward rates beyond the central bank's forecast horizon, i.e. $k \geq h$. In the online appendix, we provide a result for the impact within the forecast horizon. The sign of the short-run impact is difficult to characterize, but, in contrast to the long-run effect we characterize below, is bounded. For $k \geq h$ the variance of future nominal rates depends on the variance of $\varepsilon_{m+j}$ for $j \in\{h, \ldots, k\}$, which the market does not know on day $t-1$. Instead, it forms a forecast of these terms based on $\sigma_{m+h-1}^{2}$. IR publication then reveals $\sigma_{m+h}^{2}$, which leads the market to update its forecast on future fundamental uncertainty and thus its view on future nominal rate volatility.

The extent to which learning $\sigma_{m+h}^{2}$ affects market forecasts of long-run fundamental uncertainty depends on $\rho_{\sigma}$, the persistence of shocks to fundamental uncertainty in the model defined in (2). With low persistence, the effect of $u_{m+h}$ dies away quickly and 1 forecasts of the variance of $\varepsilon_{m+j}$ are relatively unaffected as $j$ grows past $h$. With high persistence, the opposite is true. In our next result, we characterize the largest impact 
Proposition 2 Suppose that $k \geq h$. Then the uncertainty channel satisfies

$$
\lim _{\rho_{\sigma} \rightarrow 1} U N C_{m}(k)=\phi^{2}\left\{\begin{array}{c}
\sum_{j=1}^{h} \rho^{2(k+h-j)}\left(\left(s_{m+j, t}^{M K}\right)^{2}-\left(s_{m+j, t-1}^{M K}\right)^{2}\right)+ \\
\sum_{j=h}^{k} \rho^{2(k+h-j)} \exp \left(\frac{(j-h) \sigma_{u}^{2}}{2}\right)\left[\sigma_{m+h}^{2}-\sigma_{m+h-1}^{2} \exp \left(\frac{\sigma_{u}^{2}}{2}\right)\right]
\end{array}\right\} .
$$

1 Moreover, $\lim _{k \rightarrow \infty} \lim _{\rho_{\sigma} \rightarrow 1}\left|U N C_{m}(k)\right|=\infty$ whenever $\sigma_{m+h}^{2} \neq \sigma_{m+h-1}^{2} \exp \left(\frac{\sigma_{u}^{2}}{2}\right)$.

The effect in the first line of the expression for $\mathrm{UNC}_{m}(k)$ represents a reduction in uncertainty due to additional signals on the cyclical shocks that will hit economic conditions over the next $h$ months. Its value is declining in $k$ whenever $\rho<1$ because, as with the expectations channel, the impact of short-run shocks fades away in the long run in a stationary autoregressive process.

The effect in the second line reflects the impact of revised forecasts of future fundamental uncertainty. It can be positive or negative depending on the sign of $\sigma_{m+h}^{2}-$ $\sigma_{m+h-1}^{2} \exp \left(\frac{\sigma_{u}^{2}}{2}\right)$, which captures whether IR publication increases or decreases the expected value of $\sigma_{m+j}^{2}$ for $j>h .10$ As $k$ grows, the absolute value of this effect also grows. This is because the number of shocks to fundamental uncertainty between months $m+h$ and $m+k$ increases in $k$. So fundamental uncertainty, and therefore the impact of forecast revisions, accumulates as one moves further out in the yield curve. In the limit as $k$ grows very large, IR publication induces an unboundedly large absolute change in the expected variance of the policy rate outside of the measure zero event $\sigma_{m+h}^{2} \neq \sigma_{m+h-1}^{2} \exp \left(\frac{\sigma_{u}^{2}}{2}\right)$. Our model therefore strongly suggests that news contained in central bank communication relevant for forecasting fundamental uncertainty can have a large impact on long-run term premiums. .11

The case of high $\rho_{\sigma}$ is an empirically plausible assumption; Bansal and Shaliastovich (2013) estimate a stochastic volatility model similar to ours, and find the persistence in uncertainty shocks to be well above 0.9 . We expect a similar mechanism to operate

\footnotetext{
${ }^{10}$ The change in future expected value does not depend simply on $\sigma_{m+h}^{2}-\sigma_{m+h-1}^{2}$ because $\sigma_{m+j}^{2}$ is lognormally distributed.

${ }^{11}$ Martin and Ross (2019) present a non-Gaussian bond-pricing framework in which a similar effect could arise if signals altered transition probabilities between persistent states of the world. Cieslak and Schrimpf (2019) discuss a similar channel (without formally modeling it), and the idea is also consistent with Bansal and Shaliastovich (2013) and Ellison and Tischbirek (2018).
} 
5 The model analysis presented above enables us to distinguish in the data between com6 peting theories of why central bank communication moves long-run interest rates.

at the long run, and similar results to arise, in situations with a low value of $\rho_{\sigma}$ if the central bank alternatively provides signals on the baseline uncertainty $\left(\sigma_{0}^{2}\right)$ rather than the innovations to uncertainty.

\subsection{Distinguishing theories of long-run rate movements}

\begin{abstract}
The modelanalysis presented above enables us to distinguish in the data between com-
\end{abstract}
Expectations channel. In this channel central bank communication changes modal expectations of long-run economic conditions. This is the channel emphasized in Nakamura and Steinsson (2018), and is plausible only when the central bank transmits information about shocks to highly persistent variables like the equilibrium real interest rate. Proposition 1 shows that such information should change short-run expectations at least as much as it does long-run expectations.

Uncertainty channel. In this channel central bank communication changes the perceived variance of interest rates by transmitting information on persistent uncertainty. As in Proposition 2, this information should have its largest effect on long-run rates and we expect this channel to operate through the term premium.

Investor Demand channel. This channel is not present in our model, but is modelled by Hanson and Stein (2015). In that model, the effect on long-run rates comes from a change in demand from yield-oriented investors who react to monetary news that affects short-run expectations by trading longer-term debt to maximize the yield in their portfolios. The main impact on long rates comes via the term premium but is driven by identical information to that driving the change in short-run rates.

The first two channels rely on the central bank providing direct information relevant for long-run beliefs. While the first is present in the literature, the uncertainty channel is novel. The demand channel instead relies on information relevant for short-run beliefs that then propagates to the long run through trading activity. 
While not explicitly included in the model, each Inflation Report event can be thought of as the central bank sending a vector of signals to the market, and in the next section we will explicitly construct an empirical proxy for this vector. In fact the model is silent about which signals are responsible for generating which channels, and on whether the same signal could simultaneously convey information on the level and variance of future economic conditions. For example, one signal contained in each IR is the change in the inflation forecast at the forecast horizon relative to the previous IR. From this signal, market participants may update their expectations for the inflationary state of the economy, but they may also, as a result of a large change (or non-change), update their views of uncertainty going forward. More generally, we view the total effect of any given signal the central bank sends as potentially coming from all three channels, and our empirical exercise does not attempt to argue that some channels are present while others are not. Instead, the goal is to identify which channel appears most responsible for the long-run rate reactions we observe after IR publication.

\section{Measuring Inflation Report Signals}

To use our theoretical framework to interpret interest rates moves on IR publication days we need to measure the vector of signals in the IR. Our approach is to be as flexible as possible and build a high-dimensional set of measures from both the numeric and narrative data in the IR, each of which in principle can convey news to markets. The richness of the information in the Report is crucial as it allows us to study with a great deal of granularity the information that drives different maturities in the market data and the different components (expectation and term premium) of the asset price response.

\subsection{Numeric information}

The numeric forecast information in the IR on day $t$ is the forecasts for GDP growth and inflation, which form part of $\mathbb{E}\left[\omega_{m+h} \mid I_{m}^{\mathrm{CB}}\right]$, and distributional information around them. These forecasts have been conditioned on the path for the policy rate implied by 
1

market interest rates. We focus on the projections at the two-year horizon as that is the horizon that has tended to be focused on in the Bank's monetary policy communication as the one most relevant for the current stance of policy.

In our analysis we use a set of 15 core numeric signals contained in each IR published in month $m$ which we label $\mathbf{q}_{t}$. The details on these are fully provided in Appendix $\mathrm{D}$. We divide these into two groups. The first contains seven variables that directly represent the level or news on the expectational component of the forecast: the modal growth and inflation forecasts; the surprise in these forecasts relative to market expectations; the implied output gap; and the two measures of the evolution of the output gap from the previous IR. We denote these variables $\mathbf{q}_{t}^{\mathrm{EXP}}$. The remaining eight variables represent information on the distributions around these forecasts, and broadly measure uncertainty. We label these $\mathbf{q}_{t}^{\mathrm{UNC}}$. Of course, the same set of signals can operate through multiple channels if they convey, either directly or indirectly, information on both the level and uncertainty around future economic conditions.

\subsection{Narrative information}

The narrative information in the IR consists of text broadly organized into two parts. A set of economics sections assess the current state of the economy, covering recent developments in and the near-term outlook for financial conditions, demand, supply, costs and prices. A forecast section describes the MPC's forecasts, the risks around those forecasts, and the potential trade-offs for policy. The IR does not contain explicit forward guidance, understood as an explicit commitment to a future policy rule, or even a suggested response as to how future interest rates may evolve.

The narrative information can have important effects on future expectations and uncertainty for several reasons. First, there are many hundreds of hard and soft indicators of economic activity that the MPC regularly monitors, including surveys, disaggregate activity and inflation series, and information from regional agents. These indicators are all (potentially) endogenously related to each other and to the inflation and output forecasts contained in the fan charts. The narrative in the IR provides the Bank of England's views 
about the nature of these endogenous relationships, as well as what are the key drivers of the current forecasts. This can influence market views of likely future MPC forecasts. For example, the IR can reveal whether the inflation forecast is driven by persistent or transitory price movements.

Additionally, monetary policymakers in general, and the MPC specifically, do not publish quantitative views on the value of latent macroeconomic variables such as the equilibrium real interest rate. While an important driver of the policy action, the equilibrium real rate is an inherently elusive variable that depends on quantities such as the unobserved productive capacity of the economy about which there may be significant disagreement. In this context, the narrative may be the only way the MPC can signal its view of, and uncertainty about, the level of the real rate.

Another advantage of using narrative information is that it is inherently much richer than the numeric forecasts. This allows us to capture much more precisely the different signals that central banks send to markets. However this advantage also presents several statistical challenges that we must address. These include the issue of how to quantitatively represent the text for statistical analysis, as discussed in the rest of this section. It also includes the issues of the endogeneity of text to economic conditions and forecasts, and how to determine which topics are driving interest rate changes when the topic space is high dimensional, both of which are discussed in Section 5 .

In the 70 Reports in our sample, there are 15,023 paragraphs. We first pre-process the text by removing all non-alphabetic terms, as well as extremely common words that are uninformative about the content such as 'the', 'and', and so on - so-called stopwords. We then stem each remaining term into its linguistic root using the Porter stemmer. Stems need not be an English word: for example, the stem of 'inflation' is 'inflat'. Following these steps gives us 754,884 total terms in the dataset and 4,382 unique terms.

In order to reduce the dimensionality of the dataset we represent the text using a probabilistic topic model called Latent Dirichlet Allocation (LDA), first used in the economics literature by Hansen et al. (2018) and discussed in Appendix E. LDA estimates each document $d$ to be its own distribution over topics given by $\boldsymbol{\theta}_{d}$ (each document can 
belong to multiple topics). Each topic is a probability vector over the $V$ unique terms in the data. We use a model with $K=30$ topics. We treat each paragraph as a document so we have $D=15,023$ documents in our corpus of texts with $V=4,382$ unique terms.

While we estimate LDA at the paragraph level to exploit variation across thousands of examples of text, we follow the procedure detailed in Hansen et al. (2018) to obtain the distribution over topics in the IR published on day $t$, which we denote $\boldsymbol{\theta}_{t}$. Figure E.1 in Appendix E represents the 30 topics that LDA estimates in our data and demonstrates that they are indeed interpretable (though our analysis focuses on tests that do not rely on any specific subjective labels). Topic 6, for example, appears to capture discussion of commodity prices; Topic 14 of the forecast; Topic 24 of financial markets; and so on. Since changes in topic coverage can also have potentially important market effects, we also include $\boldsymbol{\delta}_{t} \equiv \boldsymbol{\theta}_{t}-\boldsymbol{\theta}_{t-1}$ to obtain a 60 -dimensional representation of the text information in each IR - the 30 topic levels (later denoted 'L') and the 30 changes (denoted 'D').

LDA topics do not necessarily have a directional interpretation. When discussing inflation, the IR could be refering to increasing or decreasing inflation. In the baseline analysis below, we sign the topics following the procedure used in Hansen and McMahon (2016) and Thorsrud (2018). We identify the main topic of each paragraph and then count the contractionary and expansionary sentiment in that paragraph for that topic using dictionaries specific to monetary policy as in Hansen and McMahon (2016). We then aggregate expansionary and contractionary topic counts across paragraphs and use the resulting measures $\left(n_{k, t}^{+}\right.$and $\left.n_{k, t}^{-}\right)$to an form IR-specific, topic level sentiment balance measure (and its first difference $\delta_{t, k}^{ \pm}$):

$$
\theta_{k, t}^{ \pm}=\frac{n_{k, t}^{+}-n_{k, t}^{-}}{n_{k, t}^{+}+n_{k, t}^{-}} .
$$

\section{Market Impact of Inflation Report Signals}

This section presents the main empirical results. It identifies which of the IR signals extracted in Section 4 are most responsible for generating the observed rate movements 
1 and hence shed light on which channels decribed in Section 3 may be responsible. A 2 key prediction of that theoretical framework is that the signals that generate an effect 3 through the uncertainty channel can have independent effects on long-run interest rates 4 that do not move short-run interest rates, and we organize much of what follows around 5 the evidence for this. For this, we first use the signed market news (e.g. $\Delta f_{36 ; t}$ ) with the 6 signed narrative signals, but show in Section 5.3 that the results are robust to using the absolute value of the news (e.g. $\left.\left|\Delta f_{36 ; t}\right|\right)$.

From a statistical viewpoint, this is a high-dimensional regression problem since there are more signals in the IR (the 15 numeric signals and the 60 narrative signals) than there are IR publication days (70 in total, but only 69 used for analysis due to differencing across IRs to generate some signals). We therefore use regularization methods below for estimation, but we do not treat numeric and narrative information symmetrically. The numeric variables are, almost by definition, viewed by the Bank of England as informative about future economic conditions and so, while one may not be sure of the exact channels they enter, there is a strong argument for including them in the set of signals that generate any overall information effect. The narrative signals, by contrast, may or may not provide market news. For this reason, we include the numeric variables as regressors throughout the analysis, and only regularize the narrative signals.

\subsection{Numeric news signals}

We begin the analysis by estimating a regression model that explains yield curve news using just the news in the numeric information in the IR as captured by the variables in $\mathbf{q}_{t}$ described in Section 4.1. The model is

$$
\Delta Y_{k, t}=\beta_{0 k}+\boldsymbol{\beta}_{1 k}^{T} \mathbf{q}_{t}+\varepsilon_{t}^{k}
$$

where $\Delta Y_{t}$ is the change in the market interest rates (1-year spot, 3-year forward, etc.) observed on IR publication date $t$. We use the pre-defined split between forecast expectations and uncertainty forecast information to separate $\mathbf{q}_{t}$ into $\mathbf{q}_{t}^{\mathrm{EXP}}$ and $\mathbf{q}_{t}^{\mathrm{UNC}}$. 
We are not particularly interested in the coefficients on individual quantitative measures (in particular, because some of the measures are highly correlated), but rather the overall (joint) explanatory power as measured by the $R^{2}$ (R-Squared) statistic for each of the four interest rate horizons. As such, we summarise the results in the first columns of Table 1 and report the full regression analysis in Tables H.1-H.3 in the appendix.

[Table 1 about here.]

The first key result is that the forecast variables, and especially the central expectation variables, are an important driver of variance at the short-end of the yield curve, as measured by changes in the 1-year spot rate, with an $R^{2}$ statistic of over 0.5 . But the impact declines in maturity, with quite weak effects on market rates at five-years ahead and beyond. The split between expectation and uncertainty signals allows us to show that the declining explanatory power of the forecast variables is driven by a declining role of $\mathbf{q}_{t}^{\text {EXP }}$. When economic conditions follow a stationary AR(1) process (as is natural for GDP growth and inflation) and signals operate through the expectations channel, we showed in Proposition 1 that central bank communication would have its largest effect on short-run rates with a monotonically declining effect in horizon. The empirical results on the market impact of $\mathbf{q}_{t}^{\mathrm{EXP}}$ are consistent with this view.

The second key result is that, consistent with an effect through the uncertainty channel in our model, the uncertainty signals are increasingly important as we move along the yield curve. The additional $R^{2}$ from including $\mathbf{q}_{t}^{\mathrm{UNC}}$ variables is significant using an F-test. And the relative explanatory power of the $\mathbf{q}_{t}^{\mathrm{UNC}}$ variables, measured by the proportion of $R^{2}$ explained - i.e. the proportion of the total explained variance that is captured by adding those additional variables - grows with maturity of the interest rate.

We next estimate (7) separately for the two comonents of the change in market rates: the change in the expectations and the change in the term premiums (described in Section 2.2). The relative impact of the $\mathbf{q}_{t}^{\mathrm{EXP}}$ variables on expectations is not greater at the long than the short end of the yield curve, whereas the relative impact on long-run term premiums is greater than that on the short run. This result is again consistent with the uncertainty channel, which should have its largest impact via the long-run term premium. 
1 Although, one should be careful in over-interpreting the $R^{2}$ from these estimates as the

overall amount of variation in term premiums at the short end of the yield curve is very small (as discussed earlier); the $R^{2}$ in column 2 of panel (b) tells us that the overall regression is explaining about half of very little variation.

These results provide preliminary evidence that central bank communication operates through multiple channels, and that long-run interest rates appear to react to signals on uncertainty that are distinct from the signals that move short-run interest rates.

\subsection{Narrative news signals}

The analysis of the numeric forecast information is consistent with the uncertainty channel being a primary driver of longer-maturity yields. We now use the narrative signals to explore this idea more specifically, as its dimensionality provides a means to explore the different communication channels that can drive the long-run information effect (expectations, uncertainty, investor demand) in more detail.

\subsubsection{Is there news in narrative?}

Before analyzing the market impact of narrative signals, one needs to establish that they contain news at all over and above the information in the numeric forecasts. The first step is to purge variation in the signed narrative variables $\left(\theta_{t, k}^{ \pm}, \delta_{t, k}^{ \pm}\right)$that is endogenous to the numerical forecast information. For example, an increase signed inflation topic may be associated with a deviation of inflation from target in the modal forecast.

We fit the models

$$
\begin{aligned}
& \theta_{k, t}^{ \pm}=\alpha_{0 k}+\boldsymbol{\alpha}_{1 k}^{T} \mathbf{q}_{t}+v_{L t}^{k} \\
& \delta_{k, t}^{ \pm}=\beta_{0 k}+\boldsymbol{\beta}_{1 k}^{T} \mathbf{q}_{t}+v_{D t}^{k}
\end{aligned}
$$

The estimated residuals $\widehat{v}_{L t}^{k}$ and $\widehat{v}_{D t}^{k}$ represent the variation in signed topic $k$, and its change from the previous IR, not explained by the forecasts.

Our construction is similar to that in Romer and Romer (2004) and Cloyne and Hürt- 
1 gen (2016), who construct monetary policy shocks by regressing interest rate decisions

$$
\min _{\gamma_{Y}} \sum_{t}\left(\widehat{\varepsilon}_{t}^{k}-\gamma_{Y}^{T} \widehat{\mathbf{v}}_{t}\right)^{2}+\lambda\left[\alpha\left\|\gamma_{Y}\right\|_{1}+(1-\alpha)\left\|\gamma_{Y}\right\|_{2}^{2}\right]
$$

The first term is the objective function of an OLS regression of the yield- $k$ residuals on the narrative shock variables. The second term is a penalty on non-zero values of the regression coefficients $\gamma_{Y}$. The parameter $\alpha$ can range from 0 , equivalent to a ridge regression, to 1, equivalent to the least absolute shrinkage and selection operator (LASSO). The $\alpha=1$ LASSO specification is useful because it induces sparse solutions but when two or more covariates are significantly correlated it typically only generates a non-zero coefficient for one of them. We set $\alpha=0.99$ to induce a degree of sparsity akin to the LASSO, while maintaining robustness to the (relatively few) high correlations in the narrative shocks (Friedman et al. 2010).

Before estimating (10), one must choose a value for the penalty parameter $\lambda$. We use the common approach of selecting $\lambda$ using cross validation based on out-of-sample predictive performance. We describe this procedure in detail in Appendix G.1 and here focus on the results. We find that a the number of selected narrative shocks are 53,56 , 56 and 55 respectively for yields $\Delta i_{0: 12, t}, \Delta f_{36, t}, \Delta f_{60, t}$ and $\Delta f_{60: 120, t}$.

That a large number of narrative shocks is selected for each maturity suggests that

\footnotetext{
${ }^{12}$ One concern in high-dimensional regressions is that correlation among regressors can impede the ability to identify variables with a 'true' relationship with the outcome. In fact, our narrative shocks display little correlation on average.
} 
they are indeed important in explaining the yield residuals. To test that this result is not spurious, we develop a simple permutation test to compare the selected number to a distribution of the number of selected variables under the null hypothesis that narrative shocks are independent of yield residuals. Full details and results are in Appendix G.2. We conclude that there indeed appears to be important explanatory power contained in the IR narrative that is orthogonal to that in the numerical forecast variables.

This finding that there is market news in the narrative of central bank communication is of independent interest and another contribution of the paper. Most studies of central bank communication that analyze their content focus on numerical information, but there is evidence that some other factor is needed to explain the full market reaction around communication events (Gürkaynak et al. 2018). We find it natural to view narrative as an important aspect of this 'missing' information in event studies, and the approaches we develop are more broadly relevant to the literature.

\subsubsection{Testing distinct long-run information I: key narrative signals}

While we have established that narrative shocks are a source of news, we do not know which are most important for explaining market rates, nor whether these differ by maturity. The baseline elastic net regression selects nearly every shock at every maturity, 13 so we need some way of discriminating among signals according to their information content. To do this, we adopt a bootstrap procedure suggested by Hastie et al. (2015). In each of 500 simulations we draw a bootstrap sample with replacement from our original data, compute coefficient estimates using the same cross validation procedure as in the baseline, and record whether each topic variable is selected. Across all the bootstrap draws, we can compute the fraction of times that each topic variable is selected, and use this as an indicator of which variables are key in driving the market response to the IR.14 Table 2 lists the top four topic variables for each yield based on the bootstrap draws,

\footnotetext{
${ }^{13}$ This is not surprising. Meinshausen and Bühlmann (2006) show that the number of selected features from an elastic net regression estimated via cross validation may be a superset of the relevant variables.

${ }^{14}$ The elastic net regression we estimate is very similar to the LASSO, which has a probabilistic formulation as a Bayesian regression model with Laplace priors on the coefficients. The bootstrap procedure can be thought of as a shortcut for doing a full posterior simulation exercise.
} 
and reports the fraction of draws in which they appear. This reveals that the topics that are most likely to drive short and long rates differ considerably: the top topics for 1-year spot rates and 5-year, 5-year forward rates contain no overlap. We formalize this below.

[Table 2 about here.]

The most likely words within the key topics for the shortest- and longest-maturity assets, listed above in Table 2, are presented graphically as word clouds in Figures 2 and 3. While these topics do not come with labels and interpreting them is a subjective exercise, the key topics that drive the different yields are suggestive of the channels from the theoretical model. On the one hand, those that drive the 1-year spot rates appear to relate to current economic conditions and include those that vary most with the interest rate cycle (see Figure E.2). On the other hand, the key topics for the five-year ahead, five-year forward rate appear to relate to the forecasts and their uncertainty and are less cyclical. This is consistent with a model in which the central bank sends signals about the levels of mean-reverting economic conditions that affect short-run rates, and signals about economic uncertainty that affects long-run rates.

[Figure 2 about here.]

[Figure 3 about here.]

Table 3 formalizes the finding that different narrative signals drive different rate maturities. It reports the Pearson correlation coefficients between narrative shocks based on the fraction of bootstrap draws in which they are selected. The selection percentages for 1-year spot rates are in fact uncorrelated with those for the longest rates, while the selection percentages associated with all other rates are significantly correlated. Importantly, this finding casts doubt on either the expectations channel or the investor demand channel being the primary driver of long-run rate movements in response to the IR. Both channels require the signals that move short-run rates to also move long-run rates.

[Table 3 about here.] 
If the uncertainty channel drives long-run interest rates, we expect it to do so through the term premium rather than expectations, while the reverse is true of the expectations channel. We repeat the bootstrap procedure on each separate yield component, Table 4 shows the results. There is substantial overlap between the narrative signals that drive short-run movements in the overall yield change and the signals that drive the shortrun expectations component. In contrast, there is an overlap between the top long-run overall and term premium signals. Relatedly, the key signals for explaining long-run term premiums are not the key signals for explaining the overall change in short-run yields. This is further evidence that long-run rate movements do not arise solely from trading activity in response to signals driving the short end, as would be the case in the investor demand channel.

Table 5 is the analogue of Table 3 by yield component. Here we find an interesting distinction between expectation and term premium signals: the topic selection percentages for expectations are much more correlated across maturities than that of term premiums. This suggests that the results on the overall change potentially mask an underlying expectations component that reflects a rather persistent set of common signals driving short- and long-run expectations. However, this is not the dominant source of variation in long-run interest rates and suggests that, while the uncertainty channel is not the only factor driving the long-run information effect, it is the primary one.

\subsubsection{Testing distinct long-run information II: Placebo regressions}

Although we have found distinct narrative signals in the bootstrap test, one might still question whether these actually explain different amounts of movement in yield residuals. Our final test of distinct long-run information assesses to what extent the key narrative signals associated with each maturity actually explain more of the yield residual at that maturity than the key narrative signals associated with other maturities. 
In Table 6 we replicate the overall regressions in Table 1 and then compute the $R^{2}$ impact associated with adding in the top four narrative signals from Table 2. (Appendix Tables H.4 and H.5 display more details of the regressions on which Table 6 is based.)

[Table 6 about here.]

To test whether the key narrative signals at each maturity explain more yield residual variance at that maturity, we replace them with key narrative signals at other maturities, and record the additional $R^{2}$ reported as a proportion of the total variance explained by the regression. Table 7 displays the results and indicates the significance level of an F-test on the joint significance of the narrative shocks given the inclusion of $\mathbf{q}_{t}$. Here we have not accounted for the post-selection inference problem of how to conduct hypothesis tests on the significance of selected regressors from an elastic net regression. Our question of interest is not whether the selected signals at each maturity are significant in a statistical sense, but how their explanatory power compares to other narrative signals selected at other maturities. This is another way of asking whether we have selected independent signals to explain long-run rate movements.

The answer is clear from Table 7. The top narrative signals for short-run rates do not improve the overall fit for longer maturity rates; for five-year, five-year forward rates, the short-rate top topics add 0.04 to the $R^{2}\left(10 \%\right.$ of the total $R^{2}$ ) but the additional variables are not statistically significant. Likewise, the top narrative signals for long-run rates do not significantly add to the regression for one-year spot rate. The effects of the top narrative signals for the five-year forward rate and the five-year, five-year rate are similar for both maturities, which is not surprising given there is overlap in the selected topics. The bottom line is that the selected narrative signals for the long-run are not an indirect proxy for signals that move short-run rates, but distinct information. This reinforces the plausibility of the uncertainty channel.

[Table 7 about here.]

The table also shows the effect of the top topics on the separate components of the overall yield curve. This allows us to explore in more detail the impact of the expec- 
tations and investor demand channels. The narrative signals that explain the one-year spot rate, which is predominantly driven by variation in the expectations component, do not significantly explain variation overall for all other yields but they do explain the expectations component at all maturities (for the five-year forward, the additional $R^{2}$ has a p-value of 0.12). While this is consistent with a longer-run expectations channel, it is not the main driver of the overall movement in long-run rates.

The investor demand channel requires that the information that moves short-run expectations also moves the long-run term premiums. Instead, the top signals for the one-year spot rate, and particularly the expectations component, add only $4 \%$ (2\%) of the variation in the five-year, five-year (five-year forward) term premium. Moreover, the top signals for explaining the long-run term premium explain almost nothing about shortrun expectations (1\% for the one-year spot expectations component and $3 \%$ overall).

Together, the results show that the expectations channel may indeed operate, but there is little evidence of the investor demand channel. In any case, the main driver of long-run interest rates is narrative signals that explain the long run independently of any impact on short- or medium-term expectations. This long-run impact comes largely via the term premium. All of these facts point to the uncertainty channel as the primary mechanism through which the Inflation Report operates on long-run interest rates.

\subsection{Robustness}

In appendix Section I, we show that the main findings are robustness to a number of potential concerns. In particular, we show that taking the absolute value of asset price changes to measure news does not alter the main results and has the advantage of not needing to assign a tone to the topics.

Next, because our model does not consider the impact of the Zero Lower Bound (ZLB), a concern may be that in a situation where the ZLB is binding and the short-end of the yield is downwardly constrained, a signal that economic conditions will be persistently weaker can only move the yield curve further out (it should shift the short- and long-end of the yield curve equally). This would be an expectations shock that appeared to only 
move the long-end. Moreover, to the extent that the persistent weakness of the economy might signal that the economy may have switched into a new regime in which deflation risk is higher, those effects may come through a change in term premiums. To alleviate these concerns, we remove the ZLB period from our analysis (25 IR events) and show the key results from the whole sample are present in this period.

Due to lack of short-maturity real yields data, we focused on nominal rates. However, we show that, for the yields where both real and nominal data are available, consistent with the findings in Nakamura and Steinsson (2018), real and nominal yields move closely together. The correlation between the real and nominal market reactions are $0.81,0.85$ and 0.8 for the $3 y, 5 y$ and $5 y 5 y$-forward rate respectively. The implication is that inflation expectations, at least at longer maturities, do not react too much in response to the IR. Moreover, the key narrative signals which drive the nominal yield curve are significantly correlated with the key narrative signals driving the real market reaction.

As mentioned above, another concern may be that other information drives the response on the IR publication data. We show that controlling for the earlier monetary policy shock, in addtion to the numerical $\mathbf{q}_{t}$ IR data, has no effect on the results. We find evidence consistent with some movements in the longer-maturity yields as reaction to the labour market data that is sometimes released on the IR publication date, we show that this asset price reaction is in addition to the variation driven by the IR.

Finally, controlling for the discussion of forward guidance in the August 2013 and February 2014 IRs also has little effect.

The residual variation left to explain from including all these additional controls is essentially unchanged from the first stage regression without the inclusion of the extra variables; the correlations between the residuals are all above 0.9 and as high as 0.98 .

\section{Conclusion}

Communication has offered an additional tool to central banks to move interest rates faced by banks, firms and households face across a variety of different maturities. One 
mechanism for this is through the central bank conveying information about economic conditions. So far the literature on this information effect has focused on signals about the expectations of the level of economic activity. Our results show that, in addition to this conventional expectations channel, signals about the expected uncertainty around economic conditions can give rise to important effects, especially at the long-run. Using a novel combination of theory, unstructured data and event studies, we find that this uncertainty channel plays a dominant role in moving interest rates at the long-end of the yield curve in response to publication of the Bank of England Inflation Report.

These results suggest that central banks concerned with their influence on long-term interest rates should take seriously the communication of the distribution of risks and uncertainties around economic conditions. Of course, more remains to be done to understand fully the policy implications of this channel of central bank communication and, in particular, how to incorporate this into communication strategies. For instance, earlier work on Delphic forward guidance, an approach adopted by many central banks in the last decade, has stressed the need to combine views on the future evolution of the economy together with a description of how monetary policy will react to these developments whereas our results suggest policy-free guidance can also move long-run interest rates. This may be particularly important for central banks to take into account in periods when it is confronted with an effective lower bound on short-term interest rates and its influence on long-run rates is relatively more important. 


\section{References}

Baker, S. R., Bloom, N., and Davis, S. J. (2016). Measuring Economic Policy Uncertainty. The Quarterly Journal of Economics, 131(4):1593-1636.

Bansal, R. and Shaliastovich, I. (2013). A Long-Run Risks Explanation of Predictability Puzzles in Bond and Currency Markets. The Review of Financial Studies, 26(1):1-33.

Blei, D. M., Ng, A. Y., and Jordan, M. I. (2003). Latent Dirichlet Allocation. Journal of Machine Learning Research, 3:993-1022.

Blinder, A. S. (2018). Through a crystal ball darkly: The future of monetary policy communication. AEA Papers and Proceedings, 108:567-71.

Blinder, A. S., Ehrmann, M., Fratzscher, M., Haan, J. D., and Jansen, D.-J. (2008). Central Bank Communication and Monetary Policy: A Survey of Theory and Evidence. Journal of Economic Literature, American Economic Association, 46(4):910-45.

Bloom, N. (2009). The Impact of Uncertainty Shocks. Econometrica, 77(3):623-685.

Boukus, E. and Rosenberg, J. (2006). The information content of FOMC minutes. Technical report, Federal Reserve Bank of New York.

Bundick, B., Herriford, T., and Smith, A. L. (2017). Forward Guidance, Monetary Policy Uncertainty, and the Term Premium. Research Working Paper RWP 17-7, Federal Reserve Bank of Kansas City.

Campbell, J., Evans, C., Fisher, J., and Justiniano, A. (2012). Macroeconomic Effects of Federal Reserve Forward Guidance. The Brookings Papers on Economic Activity, Spring:1-54.

Carvalho, C., Hsu, E., and Nechio, F. (2016). Measuring the effect of the zero lower bound on monetary policy. Working Paper Series 2016-6, Federal Reserve Bank of San Francisco.

Cieslak, A. and Schrimpf, A. (2019). Non-monetary news in central bank communication. Journal of International Economics, 118:293 - 315.

Cloyne, J. and Hürtgen, P. (2016). The Macroeconomic Effects of Monetary Policy: A New Measure for the United Kingdom. American Economic Journal: Macroeconomics, $8(4): 75-102$.

Draghi, M. (2017). Remarks at Central Bank Communications Conference. ECB.

Drechsler, I., Savov, A., and Schnabl, P. (2018). A model of monetary policy and risk premia. The Journal of Finance, 73(1):317-373.

Ellison, M. and Tischbirek, A. (2018). Beauty Contests and the Term Structure. Discussion Papers 1807, Centre for Macroeconomics (CFM).

Fernandez-Villaverde, J., Guerron-Quintana, P., Rubio-Ramirez, J. F., and Uribe, M. (2011). Risk Matters: The Real Effects of Volatility Shocks. American Economic Review, 101(6):2530-2561. 
Friedman, J., Hastie, T., and Tibshirani, R. (2010). Regularization Paths for Generalized Linear Models via Coordinate Descent. Journal of Statistical Software, 33(1).

Gürkaynak, R. S., Kisacikoglu, B., and Wright, J. H. (2018). Missing Events in Event Studies: Identifying the Effects of Partially-Measured News Surprises. CEPR Discussion Papers DP13153, Centre for Economic Policy Research (CEPR).

Gürkaynak, R. S., Levin, A., and Swanson, E. (2010). Does inflation targeting anchor long-run inflation expectations? Evidence from the US, UK, and Sweden. Journal of the European Economic Association, 8(6):1208-1242.

Gürkaynak, R. S., Sack, B., and Swanson, E. (2005). Do Actions Speak Louder Than Words? The Response of Asset Prices to Monetary Policy Actions and Statements. International Journal of Central Banking, 1(1).

Gürkaynak, R. S., Sack, B., and Swanson, E. (2005). The sensitivity of long-term interest rates to economic news: Evidence and implications for macroeconomic models. American Economic Review, 95(1):425-436.

Haldane, A. and McMahon, M. (2018). Central bank communications and the general public. AEA Papers and Proceedings, 108:578-83.

Hansen, S. and McMahon, M. (2016). Journal of International Economics, 99:S114 S133. 38th Annual NBER International Seminar on Macroeconomics.

Hansen, S. and McMahon, M. (2018). How central bank communication generates market news. In Eijffinger, S. and Masciandaro, D., editors, Hawks and Doves: Deeds and Words - Economics and Politics of Monetary Policymaking. VoxEU.

Hansen, S., McMahon, M., and Prat, A. (2018). Transparency and deliberation within the FOMC: A computational linguistics approach. The Quarterly Journal of Economics, 133(2):801-870.

Hanson, S. G. and Stein, J. C. (2015). Monetary policy and long-term real rates. Journal of Financial Economics, 115(3):429-448.

Hastie, T., Tibshirani, R., and Wainwright, M. (2015). Statistical Learning with Sparsity: The Lasso and Generalizations. Number 143 in Monographs on Statistics and Applied Probability. CRC Press.

Jarociński, M. and Karadi, P. (2019). Deconstructing Monetary Policy Surprises - The role of information shocks. American Economic Journal: Macroeconomics, forthcoming.

Jurado, K., Ludvigson, S. C., and Ng, S. (2015). Measuring Uncertainty. American Economic Review, 105(3):1177-1216.

Laubach, T. and Williams, J. C. (2003). Measuring the Natural Rate of Interest. The Review of Economics and Statistics, 85(4):1063-1070.

Leombroni, M., Vedolin, A., Venter, G., and Whelan, P. (2018). Central Bank Communication and the Yield Curve. CEPR Discussion Papers DP12970, Centre for Economic Policy Research (CEPR). 
Martin, I. and Ross, S. (2019). Notes on the yield curve. Journal of Financial Economics, forthcoming.

Martin, I. W. R. (2013). Consumption-Based Asset Pricing with Higher Cumulants. The Review of Economic Studies, 80(2):745-773.

Meinshausen, N. and Bühlmann, P. (2006). High-Dimensional Graphs and Variable Selection with the LASSO. The Annals of Statistics, 34(3):1436-1462.

Miranda-Agrippino, S. and Ricco, G. (2015). The Transmission of Monetary Policy Shocks. Discussion Papers 1711, Centre for Macroeconomics (CFM).

Munday, T. (2019). Central Bank Communication and Higher Moments. MPhil Thesis, University of Oxford.

Nakamura, E. and Steinsson, J. (2018). High-frequency identification of monetary nonneutrality: The information effect. The Quarterly Journal of Economics, 133(3):12831330 .

Romer, C. D. and Romer, D. H. (2000). Federal reserve information and the behavior of interest rates. American Economic Review, 90(3):429-457.

Romer, C. D. and Romer, D. H. (2004). A new measure of monetary shocks: Derivation and implications. American Economic Review, 94(4):1055-1084.

Shiller, R. J. (2017). Narrative Economics. American Economic Review, 107(4):967-1004.

Tang, J. (2015). Uncertainty and the signaling channel of monetary policy. Working Papers 15-8, Federal Reserve Bank of Boston.

Thorsrud, L. A. (2018). Words are new numbers: A Newsy Coincident Index of the Business Cycle. Journal of Business 83 Economic Statistics, forthcoming.

Woodford, M. (2001). Monetary policy in the information economy. Proceedings - Economic Policy Symposium - Jackson Hole, pages 297-370.

Zou, H. and Hastie, T. (2005). Regularization and Variable Selection via the Elastic Net. Journal of the Royal Statistical Society Series B, 67(2):301-320. 


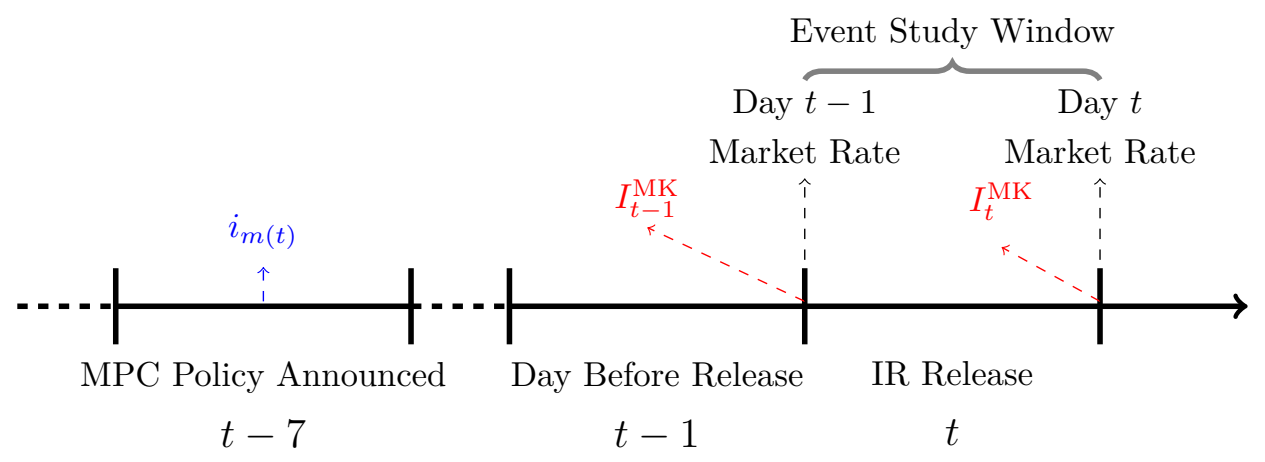

Figure 1: Event Study Time Line for IR Publication on Day $t$

Notes: This figure depicts the timeline for our event study. The policy rate in month $m(t)$, $\overline{i_{m(t)}}$, is announced a week before the IR publication. We treat the IR release as generating the change in the market information set from the close of market trading on day $t-1$ $\left(I_{t-1}^{\mathrm{MK}}\right)$ to the close of trade on day $t\left(I_{t}^{\mathrm{MK}}\right)$. This additional information generates the observed change in market interest rates on day $t$. 


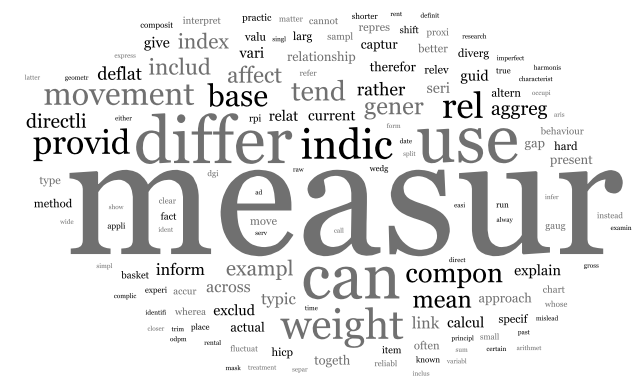

(a) D1

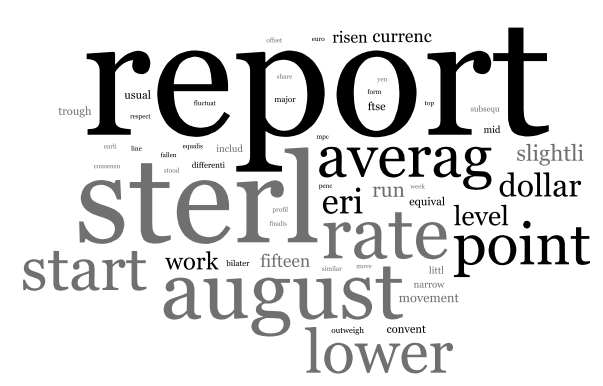

(c) D9

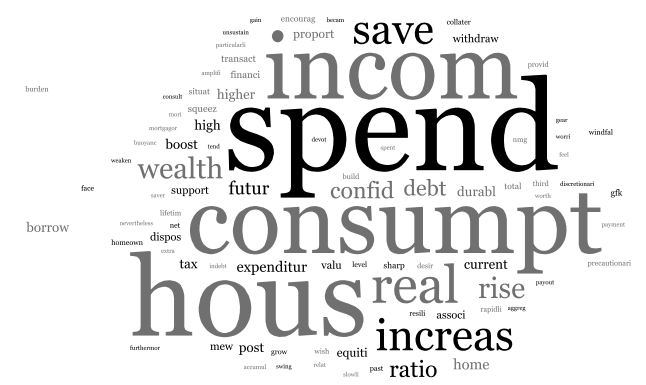

(b) L11

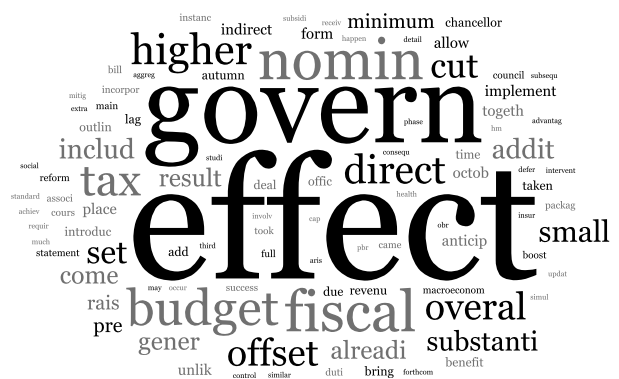

(d) L19

Figure 2: Key Topics for Market Reaction to Narrative: 1-Year Spot Rate

Notes: This figure represents the top four narrative topics explaining the residual market reaction of the 1-Year spot rate after controlling for the quantitative information. The top four topics for each yield is selected according to fraction of times they are selected across 500 bootstrap draws. The topic distributions are presented graphically as word clouds. An L indicates the topic variable corresponds to a residual in topic level $\left(\boldsymbol{\theta}_{t}\right)$, while a D indicates a residuals in the change in the topic level $\left(\boldsymbol{\delta}_{t} \equiv \boldsymbol{\theta}_{t}-\boldsymbol{\theta}_{t-1}\right)$. 


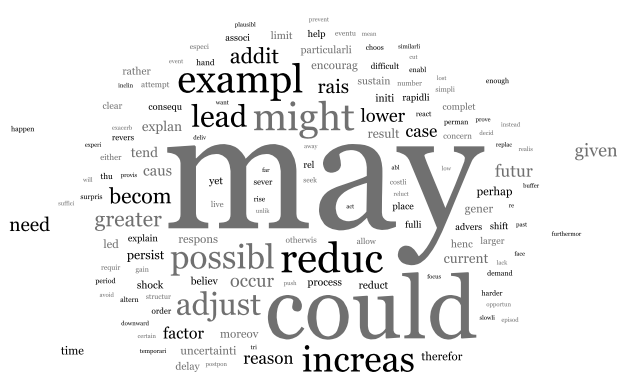

(a) L16

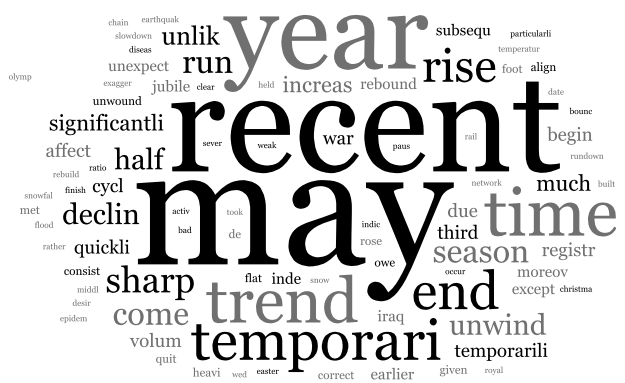

(c) L12

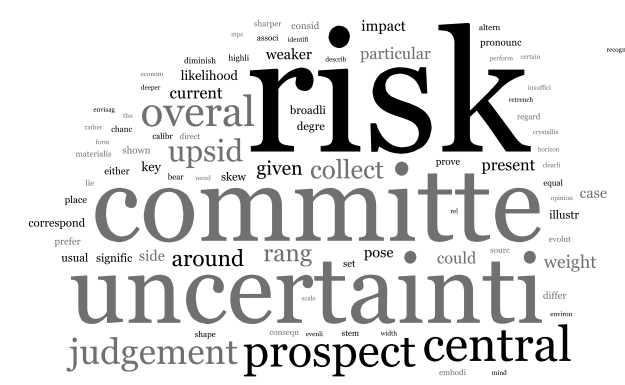

(b) D18

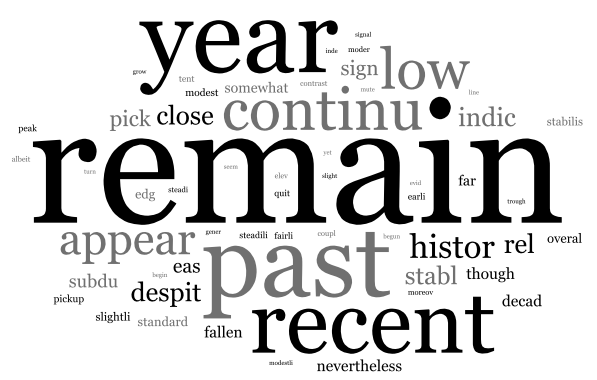

(d) D13

Figure 3: Key Topics for Market Reaction to Narrative: 5-Year, 5-Year Forward Rate

Notes: This figure represents the top four narrative topics explaining the residual market reaction of the 5-Year, 5-Year forward rate after controlling for the quantitative information. The top four topics for each yield is selected according to fraction of times they are selected across 500 bootstrap draws. The topic distributions are presented graphically as word clouds. An L indicates the topic variable corresponds to a residual in topic level $\left(\boldsymbol{\theta}_{t}\right)$, while a $\mathrm{D}$ indicates a residuals in the change in the topic level $\left(\boldsymbol{\delta}_{t} \equiv \boldsymbol{\theta}_{t}-\boldsymbol{\theta}_{t-1}\right)$. 
Table 1: Effect of Forecast Variables on Market Yields: Split by Component

\begin{tabular}{|c|c|c|c|c|c|c|c|}
\hline & \multicolumn{2}{|c|}{ Overall } & \multicolumn{2}{|r|}{ Exp } & \multicolumn{2}{|r|}{$\mathrm{TP}$} \\
\hline & & $\mathbf{q}_{t}^{\mathrm{EXP}}$ & Add $\mathbf{q}_{t}^{\mathrm{UNC}}$ & $\mathbf{q}_{t}^{\mathrm{EXP}}$ & Add $\mathbf{q}_{t}^{\mathrm{UNC}}$ & $\mathbf{q}_{t}^{\mathrm{EXP}}$ & Add $\mathbf{q}_{t}^{\mathrm{UNC}}$ \\
\hline \multirow[t]{3}{*}{$\Delta i_{0: 12 ; t}$} & $R^{2}$ & 0.45 & 0.56 & 0.45 & 0.57 & 0.26 & 0.37 \\
\hline & Additional $R^{2}$ & & $0.11^{* *}$ & & $0.11^{* *}$ & & $0.11^{* * *}$ \\
\hline & Proportion of $R^{2}$ & & 0.2 & & 0.2 & & 0.3 \\
\hline \multirow[t]{3}{*}{$\Delta f_{36 ; t}$} & $R^{2}$ & 0.26 & 0.36 & 0.33 & 0.41 & 0.06 & 0.24 \\
\hline & Additional $R^{2}$ & & $0.10^{* *}$ & & 0.08 & & $0.18^{* * *}$ \\
\hline & Proportion of $R^{2}$ & & 0.28 & & 0.19 & & 0.75 \\
\hline \multirow[t]{3}{*}{$\Delta f_{60 ; t}$} & $R^{2}$ & 0.17 & 0.33 & 0.3 & 0.39 & 0.03 & 0.28 \\
\hline & Additional $R^{2}$ & & $0.17^{* * *}$ & & $0.09 *$ & & $0.24^{* * *}$ \\
\hline & Proportion of $R^{2}$ & & 0.5 & & 0.22 & & 0.88 \\
\hline \multirow[t]{3}{*}{$\Delta f_{60: 120 ; t}$} & $R^{2}$ & 0.16 & 0.37 & 0.33 & 0.41 & 0.05 & 0.32 \\
\hline & Additional $R^{2}$ & & $0.22^{* * *}$ & & 0.08 & & $0.26 * * *$ \\
\hline & Proportion of $R^{2}$ & & 0.58 & & 0.18 & & 0.83 \\
\hline
\end{tabular}

Notes: This table summarises estimates from regressing changes in market yields on the numeric forecast variables defined in Section 4.1. The Additional $R^{2}$ captures the additional $R^{2}$ from introducing the new regressors; */**/*** denote joint significance of these regressors at the $10 / 5 / 1 \%$ significance level according to a joint F-test. The Proportion of $R^{2}$ expresses this additional explanatory power as a proportion of the total variation captured by including all the regressors. 
Table 2: Top Topics for Different Yields ( $\mathrm{L}=$ Level; $\mathrm{D}=$ Change)

\begin{tabular}{cc|cc|cc|cc}
\multicolumn{2}{c|}{$\Delta i_{0: 12, t}$} & \multicolumn{2}{|c|}{$\Delta f_{36, t}$} & \multicolumn{2}{|c}{$\Delta f_{60, t}$} & \multicolumn{2}{c}{$\Delta f_{60: 120, t}$} \\
Var & Selection $\%$ & Var & Selection $\%$ & Var & Selection $\%$ & Var & Selection $\%$ \\
\hline D1 & 0.962 & D9 & 0.932 & D9 & 0.94 & L16 & 0.946 \\
L11 & 0.942 & D18 & 0.836 & L16 & 0.89 & D18 & 0.92 \\
D9 & 0.936 & L11 & 0.824 & D18 & 0.878 & L12 & 0.844 \\
L19 & 0.92 & D13 & 0.814 & D13 & 0.87 & D13 & 0.802
\end{tabular}

Notes: This table lists the top four narrative topics explaining the residual market reaction of each yield after controlling for the quantitative information. The top four topics for each yield is selected according to fraction of times they are selected across 500 bootstrap draws. An L indicates the topic variable corresponds to a residual in topic level $\left(\boldsymbol{\theta}_{t}\right)$, while a $\mathrm{D}$ indicates a residuals in the change in the topic level $\left(\boldsymbol{\delta}_{t} \equiv \boldsymbol{\theta}_{t}-\boldsymbol{\theta}_{t-1}\right)$. 
Table 3: Pearson Correlations of Narrative Signals' Selection Percentage Across Yields

\begin{tabular}{c|cccc} 
& $\Delta i_{0: 12, t}$ & $\Delta f_{36, t}$ & $\Delta f_{60, t}$ & $\Delta f_{60: 120, t}$ \\
\hline$\Delta i_{0: 12, t}$ & 1.00 & & & \\
$\Delta f_{36, t}$ & $0.22^{*}$ & 1.00 & & \\
$\Delta f_{60, t}$ & 0.06 & $0.75^{* * *}$ & 1.00 & \\
$\Delta f_{60: 120, t}$ & 0.07 & $0.52^{* * *}$ & $0.87^{* * *}$ & 1.00 \\
\hline
\end{tabular}

Notes: This table reports the Pearson correlation coefficient of the topics' selection percentages across 500 bootstrap draws for different yields. $* / * * / * * *$ denote significance at the $10 / 5 / 1 \%$ significance level. 
Table 4: Top Narrative Signals for Different Yields (L=Level; $\mathrm{D}=$ Change)

(a) Expectations

\begin{tabular}{cc|cc|cc|cc}
\multicolumn{2}{c|}{$\Delta i_{0: 12, t}$} & \multicolumn{2}{|c|}{$\Delta f_{36, t}$} & \multicolumn{2}{c|}{$\Delta f_{60, t}$} & \multicolumn{2}{c}{$\Delta f_{60: 120, t}$} \\
Var & Selection $\%$ & Var & Selection $\%$ & Var & Selection $\%$ & Var & Selection $\%$ \\
\hline D1 & 0.97 & D9 & 0.93 & D9 & 0.938 & D9 & 0.938 \\
L19 & 0.93 & L11 & 0.868 & L11 & 0.802 & L11 & 0.85 \\
L11 & 0.92 & L24 & 0.736 & D13 & 0.758 & D18 & 0.802 \\
L28 & 0.908 & D18 & 0.714 & D18 & 0.726 & D13 & 0.762
\end{tabular}

(b) Term Premiums

\begin{tabular}{cc|cc|cc|cc}
\multicolumn{2}{c|}{$\Delta i_{0: 12, t}$} & \multicolumn{2}{|c|}{$\Delta f_{36, t}$} & \multicolumn{2}{|c|}{$\Delta f_{60, t}$} & \multicolumn{2}{c}{$\Delta f_{60: 120, t}$} \\
Var & Selection \% & Var & Selection \% & Var & Selection \% & Var & Selection $\%$ \\
\hline D13 & 0.944 & D9 & 0.854 & L16 & 0.896 & D29 & 0.88 \\
L11 & 0.91 & L16 & 0.838 & D29 & 0.816 & L16 & 0.858 \\
D9 & 0.882 & D18 & 0.838 & L12 & 0.776 & L12 & 0.85 \\
D1 & 0.864 & D13 & 0.828 & D11 & 0.774 & D11 & 0.81
\end{tabular}

Notes: This table lists the top four narrative topics explaining the residual market reaction of each yield component after controlling for the quantitative information. The top four topics for each yield is selected according to fraction of times they are selected across 500 bootstrap draws. An $\mathrm{L}$ indicates the topic variable corresponds to a residual in topic level $\left(\boldsymbol{\theta}_{t}\right)$, while a D indicates a residuals in the change in the topic level $\left(\boldsymbol{\delta}_{t} \equiv \boldsymbol{\theta}_{t}-\boldsymbol{\theta}_{t-1}\right)$. 
Table 5: Pearson Correlations of Topic Variables' Selection Percentage Across Yields

(a) Expectations

\begin{tabular}{c|cccc} 
& $\Delta i_{0: 12, t}$ & $\Delta f_{36, t}$ & $\Delta f_{60, t}$ & $\Delta f_{60: 120, t}$ \\
\hline$\Delta i_{0: 12, t}$ & 1.00 & & & \\
$\Delta f_{36, t}$ & $0.44^{* * *}$ & 1.00 & & \\
$\Delta f_{60, t}$ & $0.28^{* *}$ & $0.91^{* * *}$ & 1.00 & \\
$\Delta f_{60: 120, t}$ & $0.34^{* * *}$ & $0.89^{* * *}$ & $0.92^{* * *}$ & 1.00 \\
\hline
\end{tabular}

(b) Term Premiums

\begin{tabular}{c|cccc} 
& $\Delta i_{0: 12, t}$ & $\Delta f_{36, t}$ & $\Delta f_{60, t}$ & $\Delta f_{60: 120, t}$ \\
\hline$\Delta i_{0: 12, t}$ & 1.00 & & & \\
$\Delta f_{36, t}$ & 0.10 & 1.00 & & \\
$\Delta f_{60, t}$ & -0.06 & $0.68^{* * *}$ & 1.00 & \\
$\Delta f_{60: 120, t}$ & -0.19 & $0.40^{* * *}$ & $0.86^{* * *}$ & 1.00 \\
\hline
\end{tabular}

Notes: This table reports the Pearson correlation coefficient of the topics' selection percentages across 500 bootstrap draws for different yields and for different components of the yield curve. ${ }^{*}, * *$ and $* * *$ denote significance at the $10 \%, 5 \%$ and $1 \%$ significance levels, respectively. 
Table 6: Summary of $R^{2}$ Statistics from Yield Regressions

\begin{tabular}{|c|c|c|c|c|}
\hline & & $\mathbf{q}_{t}^{\mathrm{EXP}}$ & Add $\mathbf{q}_{t}^{\mathrm{UNC}}$ & Add Key Narrative Signals \\
\hline \multirow{3}{*}{$\Delta i_{0: 12 ; t}$} & $R^{2}$ & 0.45 & 0.56 & 0.69 \\
\hline & Additional $R^{2}$ & - & $0.12^{* *}$ & $0.13^{* *}$ \\
\hline & Proportion of $R^{2}$ & - & 0.17 & 0.18 \\
\hline \multirow[t]{3}{*}{$\Delta f_{36 ; t}$} & $R^{2}$ & 0.26 & 0.36 & 0.56 \\
\hline & Additional $R^{2}$ & - & $0.10^{* *}$ & $0.20^{* *}$ \\
\hline & Proportion of $R^{2}$ & - & 0.18 & 0.35 \\
\hline \multirow[t]{3}{*}{$\Delta f_{60 ; t}$} & $R^{2}$ & 0.17 & 0.33 & 0.5 \\
\hline & Additional $R^{2}$ & - & $0.17^{* * *}$ & $0.17^{* *}$ \\
\hline & Proportion of $R^{2}$ & - & 0.34 & 0.33 \\
\hline \multirow[t]{3}{*}{$\Delta f_{60: 120 ; t}$} & $R^{2}$ & 0.16 & 0.37 & 0.52 \\
\hline & Additional $R^{2}$ & - & $0.21^{* * *}$ & $0.15^{* *}$ \\
\hline & Proportion of $R^{2}$ & - & 0.42 & 0.29 \\
\hline
\end{tabular}

Notes: This table reports the $R^{2}$ statistics from regressing changes in market yields on $\mathbf{q}_{t}^{\mathrm{EXP}}$ (column 3), $\mathbf{q}_{t}^{\mathrm{EXP}}$ and $\mathbf{q}_{t}^{\mathrm{UNC}}$ (column 4), and the numeric forecast variables and also the top 4 topic shocks for each yield (column 5). The Additional $R^{2}$ captures the additional $R^{2}$ from introducing the new regressors; $* * * / * * *$ denote joint significance of these regressors at the $10 / 5 / 1 \%$ significance level according to a joint F-test. The Proportion of $R^{2}$ expresses this additional explanatory power as a proportion of the total variation captured by including all the regressors. 
Table 7: Placebo Regressions

\begin{tabular}{l|cccc} 
Asset News & \multicolumn{4}{|c}{ Narrative Shocks } \\
& $\Delta i_{0: 12 ; t}$ & $\Delta f_{36 ; t}$ & $\Delta f_{60 ; t}$ & $\Delta f_{60: 120 ; t}$ \\
& Overall & Overall & Overall & Overall \\
\hline$\Delta i_{0: 12 ; t}$ & $0.18^{* *}$ & 0.10 & 0.05 & 0.03 \\
$\Delta \operatorname{EXP}\left(i_{0: 12 ; t}\right)$ & $0.15^{* *}$ & 0.08 & 0.05 & 0.01 \\
$\Delta \operatorname{TP}\left(i_{0: 12 ; t}\right)$ & $0.29^{*}$ & 0.29 & 0.21 & 0.14 \\
\hline$\Delta f_{36 ; t}$ & 0.27 & $0.35^{* *}$ & $0.31^{* *}$ & 0.18 \\
$\Delta \operatorname{EXP}\left(f_{36 ; t}\right.$ & $0.26^{*}$ & $0.30^{*}$ & 0.23 & 0.10 \\
$\Delta \operatorname{TP}\left(f_{36 ; t}\right)$ & 0.17 & 0.34 & $0.39^{* *}$ & $0.34^{*}$ \\
\hline$\Delta f_{60 ; t}$ & 0.20 & $0.31^{*}$ & $0.32^{* *}$ & $0.26^{* *}$ \\
$\Delta \operatorname{EXP}\left(f_{60 ; t}\right)$ & 0.27 & $0.33^{*}$ & $0.27^{*}$ & 0.13 \\
$\Delta \operatorname{TP}\left(f_{60 ; t}\right)$ & 0.02 & 0.12 & $0.28^{*}$ & $0.30^{*}$ \\
\hline$\Delta f_{60: 120 ; t}$ & 0.10 & 0.20 & $0.30^{* *}$ & $0.28^{* *}$ \\
$\Delta \operatorname{EXP}\left(f_{60: 120 ; t}\right)$ & $0.25^{*}$ & $0.31^{* *}$ & $0.25^{*}$ & 0.13 \\
$\Delta \operatorname{TP}\left(f_{60: 120 ; t}\right)$ & 0.04 & 0.10 & $0.26^{*}$ & $0.25^{*}$ \\
\hline \hline
\end{tabular}

Notes: This table reports the proportion of $R^{2}$ gained from adding the top four narrative signals to a regression of changes in market yields on the numeric forecast variables $\left(\mathbf{q}_{t}\right)$. Each row reports the results for a different yield. Each column indicates the yields from which the top narrative shocks are estimated. For example, the cell in the bottom right of the top panel indicates the additional $R^{2}$ from adding the top four narrative shocks estimated from the 5y-5y forward rates on 5y-5y forward rate news; it is the same result as in Table 6. Stars (***, ${ }^{* *}$, and $\left.{ }^{*}\right)$ indicate the significance level $(1 \%, 5 \%$ and $10 \%)$ of an F-test on the joint significance of the narrative shocks given the inclusion of $\mathbf{q}_{t}$. 